\title{
A Model of Creative Thinking Enhancement for Teachers in Primary Schools under Bangkok Metropolitan Administration
}

\author{
Phra Choosak Thiradhammo (Laoheng) ${ }^{1}$, Somsak Boonpoo ${ }^{2}$, Sin Ngamprakhon $^{3}$, Teeraphong \\ Somkhaoyai ${ }^{4}$ \\ ${ }^{1,2,3}$ Faculty of Education, Mahachulalongkornrajavidyalaya University, Thailand \\ ${ }^{4}$ Nakhon Si Thammarat Campus, Mahachulalongkornrajavidyalaya University, Thailand \\ 1'chaibie2529@ hotmail.com, ${ }^{2}$ somsak.boo@mcu.ac.th, ${ }^{3}$ sin.ngm@mcu.ac.th, ${ }^{4}$ therapong.som@mcu.ac.th
}

\begin{abstract}
Objectives of this research are 1) to study the creative state of teachers, 2) to develop a model for promoting creativity for teachers, 3) to propose a creative promotion model for primary school teachers. Mixed methods research is used for the design. Quantitative research data has been collected from 205 samples whereas qualitative data has been collected by interviewing 10 key informants and holding focus group discussion held with 9 experts. Results found that the teachers had high opinions on their creativity namely experience in teaching and thinking and practice to learn and try to stimulate knowledge. Teachers can always listen to other people's opinions for a reason, bringing old knowledge to think modifying and apply it to something new interested in teaching in the 21 st century, teaching by using google classroom, confident in thinking, making decisions to do things. To achieve the goals set can adapt to suit various situations and environments for teachers with creative features, including being active in thinking. Flexible thinking initiates curiosity, confidence in oneself with 5 activities to promote creativity of teachers offers a model to promote creativity for primary school teachers. There are 4 parts: part 1, the lead part is environment, policy, vision, mission, principle, objective. Part 2, a model consisting of 5 aspects of creativity, namely, thinking fluency, flexible thinking including 5 activities for the development of thinking fluency, activities for developing flexible thinking, activities for developing initiative. Part 3, the application process is decision structure on the principle of success. Part 4, conditions for success, it depends on the context of the primary school.
\end{abstract}

Index Terms

Creative Thinking, Enhancement, Bangkok Metropolitan Administration

Article Received: 10 August 2020, Revised: 25 October 2020, Accepted: 18 November 2020

\section{Introduction}

Thinking is very beneficial to human life. It Will help how to solve the problem and be able to make an appropriate and rational decisions In today's rapidly advancing news and technology age when there is a high competition. Thinking and promoting thinking of children and young people is very necessary. From kindergarten to advanced level [1], which is consistent with the view that Thinking ability distinguishes humans from animals. Able to solve problems for themselves, Able to think of new inventions, Can create happiness for oneself and protect oneself from natural disasters [2]. Creativity is a process of the human brain, that is important to the human world. Creativity has created many new things, whether it is a theoretical concept. Various technological innovations are all caused by human creativity . Creativity is a very important thought power if it has been developed and promoted in a systematic manner.

As is mentioned in point 2, there is creativity Curious, love to read, write and research. In addition, students' competency is defined as item 2 . The ability to think as a concept. Ability to think critically, Synthetic thinking, Creative thinking, Critical thinking, and systematic thinking can be clearly seen from the provision of basic education. According to the basic education core curriculum, BE 2551 at the elementary level (Secondary School Grade 4-6) is an educational level that focuses on students exploring aptitudes, and their own interests. Promotion of the development of personal personality requires critical thinking skills. Creative thinking and thinking to solve problems requires living skills and skills to use technology as a learning tool Las well as social responsibility. There is a balance of knowledge, ideas, virtues and pride in order to complete a Thailand. The aforementioned characteristics also are necessary as a basis for a career or further study. The Office of the Basic Education Commission has established standards and indicators of thinking. The basic education level or internal quality assessment standard is set out in Standard 4 of the School Quality Assurance, which provides students with critical thinking ability, thinking by synthetic, critical, creative pondering and having vision, with a second indicator of creativity Optimistic and imaginative [3]

Nowadays, creativity is an essential skill in life. Creativity will help Allowing us to be successful in life. It will help us learn unhappiness with what we were and try to improve ourselves. Creativity can create a wide variety of things, including art, music, literature, innovation in science and technology, etc., all are the products of creativity. Based on above explanation it can be found that creativity is very important Education management according to the National Education Act B.E. 2542, revised and amended in 2002, which adheres to the learner-centered learning principles. [4]

Life-long continuous learning through self-knowledge encourages critical thinking and creativity under Section 7, which addresses the learning process. That it aims to instill correct awareness about politics and government in a democratic system with the King as Head of State having a pride in being Thai including promotion of religion, arts, 
and culture of the nation, sports, local wisdom; Thai wisdom and universal knowledge As well as conserve natural resources and environment, having the ability to make a career Self-reliance, being creative, a constant pursuit of self-learning and learning.[5]

National Education Management Plan 2017-2036 In strategy 3 , the development of potential of people of all ages and building a learning society. Its goal is to include students' basic skills and characteristics of Thai citizens and 21st century essential skills and traits, with key indicators such as learner qualifications and skills. Learn to gain quality and standards educational institutions / early childhood development centers organize activities in line with the early childhood curriculum and the children's competencies linked to the quality standards of early childhood in ASEAN Educational institutions at the basic education level that provide curriculum-based education aimed at developing learners with additional characteristics and learning skills in the $21 \mathrm{st}$ century. and educational institutions at the vocational and higher education level that provide curriculum-based education aimed at developing people to learn to increase competencies etc. The National Education Management Plan, promoting creativity for children and youth in educational establishments is of great importance to the development of Thailand in the Thailand 4.0 Age.[6]

From the background and importance of the problem the researcher is therefore interested in studying a model for promoting creativity for elementary school teachers under the Bangkok Metropolitan Administration in order to serve as a guideline for promoting creativity for teachers in educational institutions in order to apply such creativity to the body of knowledge for the development of teaching, self-development, social development, national development and also continue to prosper and sustain.

\section{Research Objectives}

1. To study the creative state of elementary school teachers under Bangkok Metropolitan Administration.

2. To develop a model for promoting creativity for primary school teachers under Bangkok Metropolitan Administration.

3. To propose a model for promoting creativity for primary school teachers under Bangkok Metropolitan Administration.

\section{Research Methods}

Step 1: To study the creative state of primary school teachers by 3 steps: 1) to study documents on the creative state of primary school teachers, from the data source: books, articles, textbooks, research work, website, tools: study form, document analysis: content analysis, content analysis 2) to give questionnaires about the creative state of primary school teachers, from 205 primary school teachers, and 3) to interview about the creative state of teachers with 10 primary school administrators.

The step2: To develop a creative promotion model for primary school teachers administration by 2 steps: 1) Drafting a model to promote creativity for primary school teachers: Results from Objective 1 Tool study Document Data Analysis: Content Analysis and 2) Developing by discussion group Source: Experts / Scholars / School Directors By selecting a specific type of criteria for the selection of 10 persons.

Step 3 :To propose a creative promotion model for primary school teachers such as revising and presenting together with the advisor / advisors. Data analysis: content analysis, Outcome: Creativity model for primary school teachers, Complete affiliation of Bangkok Metropolitan Administration

\section{Research findings.}

1. The study results of the creative state of primary school teachers under Bangkok Metropolitan Administration. The research results are found that overall, the teachers 'opinions on the teachers' creativity are at a high level, ranked in descending order, Self-confidence The curious side thinking, fluent Initiative and flexible thinking, as shown in Table 1 as follows,

Table 1 shows the mean and the standard deviation of the respondents based on their opinions about the creative state of primary school teachers in all 5 aspects

\begin{tabular}{c|l|l|l|l}
\hline \hline \multicolumn{2}{l}{ Variable studied } & $\overline{\mathrm{X}}$ & S.D & level \\
\hline 1. & Thinking as fluent & 3.74 & 0.779 & High \\
\hline 2. & Thinking Flexibility & 3.68 & 0.873 & High \\
\hline 3. & Initiative aspect & 3.71 & 0.937 & High \\
\hline 4. & Curiosity & 3.82 & 0.741 & High \\
\hline 5. & Self-confidence & 3.86 & 0.759 & High \\
\hline \multicolumn{2}{|c|}{ total } & 3.76 & 0.605 & High \\
\hline \hline
\end{tabular}

2. Flexible thinking, there are 3 rankings are always willing to listen to other people's opinions for a reason. There is an idea of details to decorate or expand the main idea to get a more complete meaning and have the ability to think and solve immediate problems in a timely manner. The one with the least comments is the idea of flexibility in modifications, and able to think of various kinds able to adapt from one thing to many things well and interview results. It is the ability to modify knowledge or experience for many benefits which are useful for problem solving. The development of flexible thinking through the use of a continuous thinking development program. The process of organizing ideas and content producing ideas in various forms transforming things to develop ideas

3. Initiative aspect arranged from 3 ranks, including using old knowledge to think and modify and apply it to something new, like to learn to create new things all the time, and having the courage to think and try to test their thoughts The one with the least opinions is creative, and finds a way to produce results, and the results of the interview are to be independent, i.e. Put yourself outside the bounds, rules, frameworks, and shields. Think more because it will enhance the experience. Rely on concentration and mindfulness, free from prejudice, social values, and assessment. Can fight other people's blemishes not giving time to rush thoughts too much, and not looking for profit from ideas.

4.Curiosity In order of 4 ranks: enthusiastic at Will always ask about new things, Want to meet with enthusiasm 
wanting to learn everything, and sensitive to what he saw and expresses with fondness for experimentation, study, research, questioning all the time. The least comment on was there was a surprising amount of doubt on the merits. And the results of the interviews were drawn from interests such as the 21 st century teaching, teaching by using google classrooms, based on interest. Learning in the subject continuous practice of interest which will be of great benefit to the development of teachers' creative thinking processes. 5. Self-confidence, having three ranks: Confident in thinking of decisions to take action. To achieve the goals set can adapt. It is suitable for various situations and environments.

2. Develop a model for promoting creativity for primary school teachers. Bangkok Metropolitan Administration consists of 4 parts as follows,

Part 1: The leading part consists of the environment (Environment), i.e. general conditions affecting the adoption of the model, which must be favorable, such as policy, vision, mission, etc. The difference between the characteristics of the administrators and teachers. Principle is the basic concept. And conditions of use conditions for successful implementation of the pattern and precautions to prevent problems that may arise. This is a practice to achieve success in operating 10 Objectives (Object), namely the goal of developing, a model to solve a particular problem. or to enable the operation to produce good results either. There are 7 benefits of the importance of creativity.

Part 2: The model is a feature of 2-dimensional creativity. Flexible thinking Initiative Psychological and personality dimensions consist of curiosity. Self confidence Management Process: methods of operations, activities, and others that must be performed in order to achieve the objectives of the model, including development and performance stages. And 5-step performance evaluation process; and 5 activities for promoting creativity of teachers: 1) Activity for developing thinking fluency, "analyzing, teaching synthesis", 2) activity for developing flexible thinking "creativity. 3) Activity for developing the initiative "Invention in the household" 4) Activity for developing curiosity "Good in the community" 5) Activities for developing self-confidence. "Own leadership"

Part 3 : steps to apply are 1) Structure (Structure) is the mutual link between various elements. That will help make the model more effective, namely decentralization, administration and management of educational obligations. School administration in 4 departments, which are (1) academic administration comprising 17 duties. (2) Budget management. comprising 22 duties (3) personnel management. comprising 20 duties (4) management, general administration comprising 22 duties. 2) Decision Making refers to the process of choosing one of the many options considered, or well assessed that I a way to achieve the objectives and the goal of the pattern which has decision criteria, which is a fundamental factor that makes elementary school under Bangkok Metropolitan Administration successfully implemented a creative promotion model for primary school teachers, under the Bangkok Metropolitan Administration to practice 4 areas 3) Evaluation guidelines, formulation of guidelines and tools for model evaluation for the benefit of checking how much the format functions as designed.
Part 4 : Success Conditions it depends on the context of the elementary school, under the Bangkok Metropolitan Administration, such as, vision, policy of primary school administrators.

3. Propose a model to promote creativity for primary school teachers, under Bangkok Metropolitan Administration, including as follows,

Part 1 : Preface 1) Environment is the general condition affecting the adoption of the model, such as policy, vision, mission, etc.differences between the characteristics of the administrators and teachers 2) Principle (concept) Basis and conditions of use of conditions for successful implementation of the pattern and the precautions to prevent problems that may arise, namely, the principles for success in performing work depending on individual character and attitude .

Part 2 : Model 1) Characteristics of creativity are 1) thinking fluency. having fluency in expression, quickly assembling words together to get the desired sentence, able to trace messages using fluent words, able to quickly figure out, and finding ways to improve work that are the best and most suitable gain experience in teaching and practice 2) Flexible thinking to ; thinking freely freedom, to think outside the box, can think for adapting from one thing to many things for many benefits.3) initiative. Bringing old knowledge to think modifying and apply it to something new. The practice of interest which can be very helpful. 5) self-confidence, express confident in thinking of decisions to take action. To achieve the goals set can be adapted.

Part 3 : Steps to apply 1) Structure (Structure) is the mutual link between various elements, that will help to make the model more effective, namely decentralization, administration and management of educational obligations. School administration in 4 departments, which are 1) academic administration comprising 17 duties. 2) Budget management comprising 22 duties 3) personnel management comprising 20 duties 4) management, general administration comprising 22 duties.

Part 4 : Success Conditions it depends on the context of the elementary school, under the Bangkok Metropolitan Administration, for example, vision, policy of primary school administrators Under Bangkok Metropolitan Administration (Table 1), as shown below :

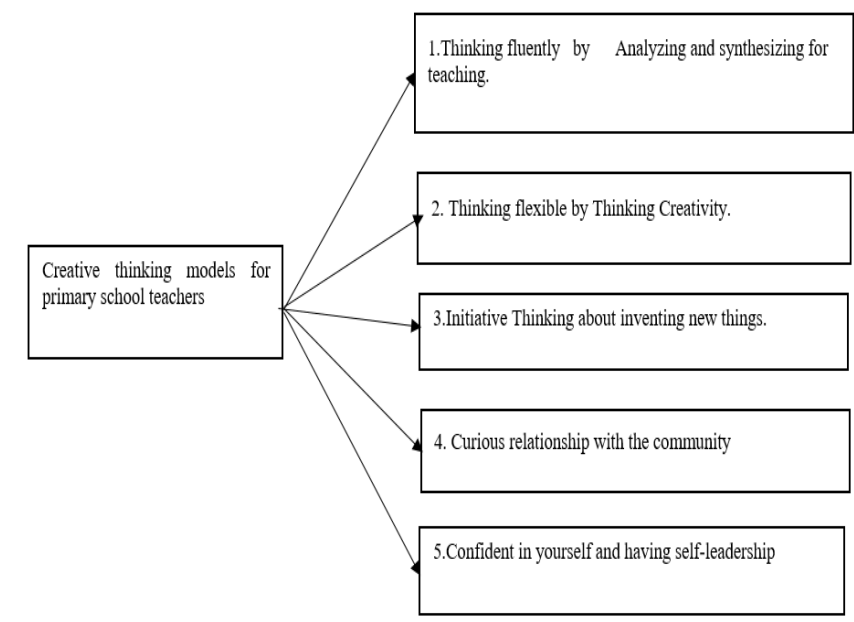

Table 1: Creative thinking models for primary school teachers. 


\section{Discussion}

The researcher found important points to be discussed about models for promoting creativity for primary school teachers, under Bangkok Metropolitan Administration as follows

1. The study results of the creative state of primary school teachers under Bangkok Metropolitan Administration are found that Creative state of elementary school teachers under the Bangkok Metropolitan Administration is of conclusion, the teachers opinions on the teachers' creativity is at a high level, ranked in descending order. Selfconfidence The curious side Thinking, fluent Initiative and flexible thinking included as indicated.

1) thinking fluency makes fluency in expression gathering experience in teaching and thinking and practice to learn and try to stimulate knowledge. By flexible thinking aspect, you can always listen to other people's opinions for a reason. Continuous thinking development activity programs Initiative Bringing old knowledge to think modifying and apply it to something new, for instance releasing yourself, taking oneself outside the bounds, rules, frames and shields of curiosity. Enthusiastic will always ask about new things with an interest in such matters as interested in teaching in the 21 st century such as Self-confidence, express confident in thinking of decisions to take action. To achieve the goals set up can adapt suitable for various situations and environments ready to take risks .Dare to do something better than admit one's mistakes .Thinking about things that are important to us and the goals we wanted to achieve.

In addition, the ability to think creatively and independently is associated with a dislike of teachers. Sometimes there is a feeling of despair for the teacher and students with creative thinking ability too. Higher self-esteem will have confidence in academic ability in all subjects, and most has a greater commitment to higher education planning than students who have the ability to Self creativity, and finally, students with a level of creative thinking ability. Higher education enters the school after academic studies and after completing group activities.Anything related to research and creative practice will be discussed further. [7]

2. Development model for promoting creativity for primary school teachers under Bangkok Metropolitan Administration, The development of the model consists of 4 parts:

Part 1: consists of the environment, general conditions affecting the adoption of the model which is favorable, such as policy, vision, mission, etc. The difference between the characteristics of the management and Principle: Basic concepts and conditions of application. Conditions for successful implementation of the pattern and precautions to prevent problems that may arise. This is a practice to achieve success in operating 10 objectives, namely the goal of developing a model to solve a particular problem or to enable the operation to produce good results either. There are 7 items for benefits of the importance of creativity.

Part 2: The model is a feature of 2-dimensional creativity. Flexible thinking Initiative Psychological and personality dimensions consist of curiosity. Self confidence Management Process: methods of operations, activities, and others that must be performed in order to achieve the objectives of the model, including development and performance stages, and a 5-step performance evaluation process including 5 activities to promote creativity of teachers.

Part 3: steps of implementation are 1) Structure (Structure), namely the mutual link between various elements. Which will help make the model more effective, namely decentralization, administration and management of educational obligations. School administration in 4 departments, which are 1) academic administration comprising 17 duties. 2) Budget management. comprising 22 duties 3) personnel management comprising 20 duties. 4) Administration, general administration comprising 22 duties. Anyone who hopes for success must complete oneself by the so-called power, which is classified in 4: contentment, love for it, persistence, persistence in it, mindfulness, attention to it, observance of reason.

Part 4 : conditions for success it depends on the context of the primary school, for example, vision, policy of primary school administrators. The above research results are consistent with Poonyarat Sirinupong's research, studying the creation of multimedia games for the development of creativity for early childhood. Early childhood cognitive design where activities within the game encourage children to think. Expresses in a fun way of creativity the efficiency passed the 90/90 standard, which is $98 \%$ of all players' average scores on the post-game test and $90 \%$ of the players passed the learning objective. [8]

3. Propose a model to promote creativity for primary school teachers under Bangkok Metropolitan Administration, as follows

Part 1:Preface 1) Environment (Environment) is the general condition affecting the adoption of the model, such as policy, vision, mission, etc. Differences between the characteristics of the administrators and teachers 2) Principle (concept) Basis and conditions of use of Conditions for successful implementation of the pattern and the precautions to prevent problems that may arise, namely, the principles for success in performing work depending on individual character and attitude. Those who will be successful in doing their job should start with changing their attitude about themselves. 3) Objectives: The goal of developing a model to solve a particular problem, or to enable the operation to produce good results with the benefit of the importance of creativity.

Part 2 :steps to apply 1) Structure (Structure) is the mutual link between various elements, Which will help make the model more effective, namely decentralization, administration and management of educational obligations. School administration in 4 departments, which are 1) academic administration comprising 17 duties. 2) Budget management. comprising 22 duties 3) personnel management. comprising 20 duties 4) management, general administration comprising 22 duties as follows, 1) Decision Making means the process of choosing one of the many options considered, or well assessed that as a way to achieve the objectives and the goal of the models. 2) Evaluation guidelines formulation of guidelines and tools for model evaluation for the benefit of checking how much the format functions as designed. The principle of Buddhism is the principle of power 4 , namely 1 . contentment, love, and love for that. 2. persistence in that thing, in the creativity of the work to accomplish. 
Par 3: Success conditions, it depends on the context of the elementary school for example, vision and management .The findings of the above research indicated that the model for promoting creativity for teachers requires activities and encouragement of teachers' creativity. Project to develop creativity for teachers to be able to develop and apply what has been trained. Used in teaching and learning to primary school children by the results of this research are consistent with the research of Lung infection (2007). The development of creativity of students Grade 1, using art learning activities, target groups used as students, found that students studying with a plan for learning about the arts to develop creativity after studying higher than before studying effectively. The significance at the .01 level and also consistent with Somporn Limcharoen (2009). "Development of supplementary curriculum to promote creativity for second graders" [9]

The research results are found that getting elements of creativity that encourage students. This creative idea consists of two dimensions: 1) dimensions of thinking, including thinking fluency, mindfulness, flexibility and initiative and 2) dimensions of mind and character, aging, craving and self-confidence. The results indicated that the experimental group had a higher average score of creativity than the group of students. The control is statistically significant at 0.05 level. The supplementary course is at a very good level. The supplementary curriculum evaluation is found to be effective according to the specified criteria. After the experiment, the researcher improved the timing and language teaching plans in explanation in some lesson plans to make it more appropriate. Then prepared a supplementary course to promote complete creativity. This is the innovation of teachers' creativity to improve teaching and learning. [10]

\section{Conclusion}

A model for promoting creativity for elementary school teachers under Bangkok Metropolitan Administration consists of 4 parts: the first part is the environment, policy, vision, mission, principle, objective, part 2 : the model is the five aspects of creativity, namely, the fluent thinking. Flexible thinking aspect Initiative, Part 3 : The curious side Self-confidence Management processes and 4: Activities to promote creativity of teachers: Activity for developing thinking fluency, "Analyzing, Synthesis, Teaching" Activity for developing flexible thinking "Thinking out of the box", Activity for developing the initiative "Basic household invention", Activity for developing curiosity. I would like to see "good things in the community" activities for developing self-confidence, "own leadership". By relying on the principle of success, which is the base of success; It depends on the context of the elementary school under the Bangkok Metropolitan Administration, for example, vision, policy of primary school administrators under Bangkok Metropolitan Administration

\section{References}

[1] Susaoraj, P. (2008). Thinking Development. Bangkok : 9119 Technique Printing Limited Partnership Printing House. (in Thai)

[2] Tatthong, K. (2011). Teach Thinking : Learning management for teaching thinking. Bangkok : Petchkasem Publishing. (in Thai)

[3] Ministry of Education. (2008). Indicators and learning area of Occupations and Technology on The Basic Education Core Curriculum B.E. 2551 (A.D. 2008). Bangkok : Thai Agricultural Co-op Printing House. (in Thai)

[4] Office of the Basic Education Commission Basic Education Curriculum 2008, Bangkok: Publishing House of Agricultural Cooperatives Association of Thailand, 2009.

[5] Office of the Education Council Secretariat Ministry of Education, National Education Plan 2017-2036, Prik Wan Graphic Co., Ltd., Bangkok, 2017.

[6] Torrance E.P. Rewarding creative behavior: experiments in classroom creativity.Englewood cliffs, N.J.: Prentice Hall inc., 1965.

[7] Somporn Limcharoen, Development of additional curriculum to promote creativity for students in the second level, Ph.D. Thesis (Research and Curriculum Development), Bangkok: Srinakharinwirot University, 2009.

[8] Poonyarat Sirinupong, creating multimedia games for the development of creativity for early childhood, Master of Arts Thesis (Media Art and Media Design), Graduate School Chiang Mai University, 2008.

[9] Kriengsak Charoenwongsak Synthetic Thinking, Bangkok: Success Media Jari Suwatthi. (1991), Courage to Think Bangkok: Department of Curriculum and Instruction, Faculty of Education. Srinakharinwirot University, Prasarnmit, 2002. 